\title{
Investigation of Shock Wave Parameters at Explosives Blasts in the Tubes with Air
}

\author{
Boris Khristoforov \\ 119334 Moscow Leninsky street 38/1 Institute of Geosphere Dynamics RAS \\ *Corresponding author: khrist@idg.chph.ras.ru
}

Copyright $@ 2013$ Horizon Research Publishing All rights reserved.

\begin{abstract}
The optimum conditions of use of the high explosive blasts in tubes with air for technology and modeling were researched. The experimental studies and calculations parameters of the direct, reflected, and outgoing shock waves at blasts on the open and closed ends of the tubes of different lengths and diameters were carried out. Comparisons the parameters of shock waves in tubes and at contacting blasts were conducted. The possible advantages of the use of explosives blasts in the tubes as compared with the contacting blasts in a variety of technical applications were investigated.
\end{abstract}

Keywords Explosive, Blast, Tube, Shock Wave, Experiment, Pendulum, Sensor, High- Speed Photography, Calculations, Technical Applications

\section{Introduction}

Blasts of explosives in the tubes were made for work out the methods blast stamping and determining the dynamic strength of metals and alloys, modeling of mechanical loads on the barriers caused by irradiation pulse high-power lasers on the plasma modes and of blast rocket engines. An ability to concentrate and direct the action of the blast in tubes is used in oil and gas wells, construction of tunnels, in rocket engines, modeling of natural and technical processes an explosive type, including blasts of fuel in transport tunnels. The blast stamping of plates are used in the engineering works. Due to increase efficiency of operation the blasts in tubes it possible to abandon of the blast basins and chambers, simplify the manufacturing.

However, these applications usually used brisance action of contacting blasts [1]. The determination an energy of blast explosives in relation to the movement of missiles 'was carried out in [2]. Analysis of blast waves for the detonation propulsions was investigated in [3]. Those works are devoted both to the creation and use of a small - size reactive blast complex. Study the effect of properties of the source on the action of blasts in air and modeling of impact of space dust and debris on flying vehicles and their components were carried out in $[4,5]$. Modeling the action of X-ray radiation on the walls of explosion chambers of pulsed nuclear power plants by contacting blasts was performed in [6]. An approximate theory of explosives blast in tubes with gas was given in [7]. The discrepancy between the calculated and measured trajectory of explosion shock wave was less than $10 \%$, when the gas mass was smaller than the mass of explosion products. The results of measurements of shock waves parameters inside tubes with air at the blasts of powerful explosives at their open end are given in [8].

Below are given results of measurements and calculations parameters of direct, reflected and flowing out shock waves at the output of the tubes with air at the blasts powerful explosives on their open and closed ends, which are commonly used in technical devices.

\section{Statement of the Tests}

The experiments were conducted with different tubes, charges and methods of measurement in air at atmospheric pressure at air mass more mass of product blast. Below shows the data for the blasts conducted in the center of the inlet section of steel tubes of length $\mathrm{L}=1,0$ and $0,5 \mathrm{~m}$, radius $\mathrm{r}=0,075$ and $0.046 \mathrm{~m}, \mathrm{~S}=\pi \mathrm{r}^{2}=0,0177$ and $0,00664 \mathrm{~m}^{2}$. A photo a shock wave flowing out from the tube after the blast is shown on figure 1. Typical schemes of the experiments are shown on figure 2 .

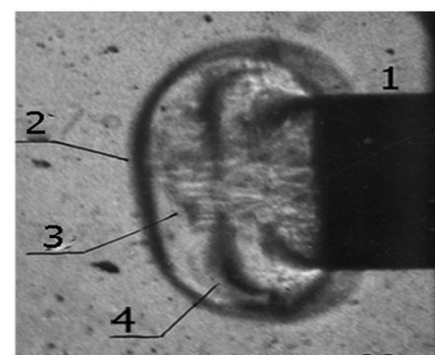

Figure 1. Photo of a shock wave is flowing out from the tube after the blast. 1 - output part of the tube, 2 - shock wave front, 3 and 4 - fluctuations after front of shock wave. 
Charges of plastic explosive had a heat of blast $\mathrm{Q}=4,8$ $\mathrm{MJ} / \mathrm{kg}$, a density $1600 \mathrm{~kg} / \mathrm{m}^{3}$, explosive mass $\mathrm{m}$ in the range from 0,001 up to $0,016 \mathrm{~kg}$. The impulses of the reflected shock waves were determined from the deviation of the pendulum and the overpressure $\Delta \mathrm{P}_{\mathrm{M}}$ was measured by face piezoelectric sensor in the center on the pendulum as shown in figure $2 \mathrm{a}, \mathrm{b}$. The knife piezoelectric sensor measured the overpressure $\Delta \mathrm{P}_{\mathrm{m}}$ of flowing out shock waves (figure $2 \mathrm{~d}, \mathrm{c}$ ). Sensitive elements sensors were from quartz or various piezoelectric. Calibration of the sensors carried out on the press or blast in the blast chamber. Different recording

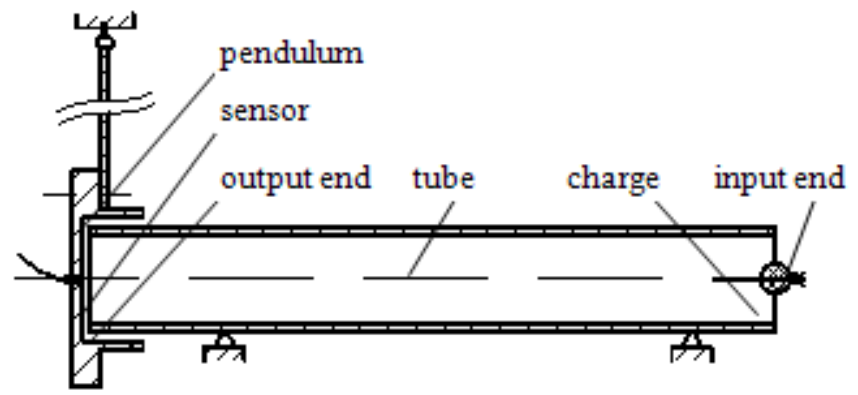

a)

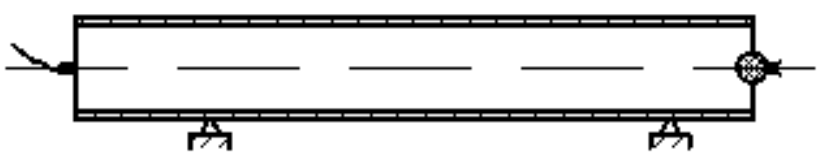

c) equipment with a frequency band up to $10 \mathrm{MHz}$ was applied.

The data of high - speed photography were using for measuring hodograph and parameters of the shock waves front, forming plane shock wave at spherical blast in tube. Was used industrial camera SFR-2M with frequency of shooting up to $2.510^{6} \mathrm{frames} / \mathrm{s}$ or in the version streak camera with resolution up to $210^{-8} \mathrm{~s}$. Equipment complex applied to measure the actions of blasts in different environments is outlined in [4 - 6, 8 - 10]. Errors of single measurement by different methods were not exceeding $10 \%$.

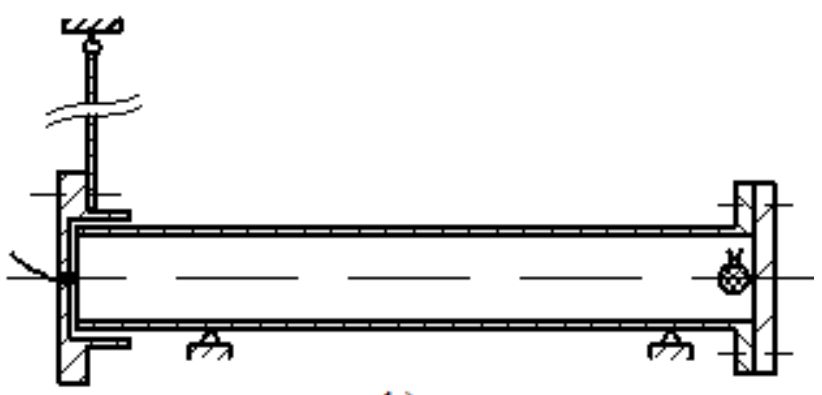

b)

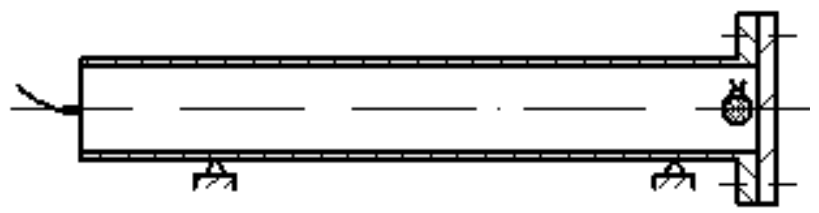

d)

Figure 2. Schemes of experimental setups. Blasts at opened and closed ends of the tubes with pendulum $-\mathrm{a}, \mathrm{b}$. Blasts at opened and closed ends of the tubes without pendulum $-\mathrm{c}$, d.

\section{Results of Tests}

The results of the measurements are shown in tables 1, 2 and figures 3-5, where introduced the following notation: I impulse of reflected shock waves determined from the pendulum deviation in Ns, I/m - relative impulse in $\mathrm{m} / \mathrm{s}$ ("relative" indicating relative to $\mathrm{m}$ - mass of explosive), $\mathrm{J}=\mathrm{I} / \mathrm{S}$ - specific impulse in Pa.s, $\Delta \mathrm{P}_{\mathrm{M}}$ - overpressure of reflected shock wave measured on pendulum by sensor in $\mathrm{MPa} . \Delta \mathrm{P}_{\mathrm{m}}, \tau_{+}, \mathrm{J}_{+}$- overpressure, duration and specific impulse positive phase of the shock waves were measured by piezoelectric sensors at outlet tubes without the pendulum. $\mathrm{X}$ - distance from charge to front of shock wave in $\mathrm{m}, \mathrm{mQ}$ - explosive energy in $\mathrm{kJ}, \mathrm{E}$ - specific energy of blast in tube in $\mathrm{MJ} / \mathrm{m}^{2}$. 
Table 1. Results of measurements the parameters of reflected shock waves in tubes on the pendulum.

\begin{tabular}{|c|c|c|c|c|c|c|c|c|c|c|c|c|c|c|}
\hline $\begin{array}{c}\mathrm{m}, \\
10-3 \mathrm{~kg}\end{array}$ & $\begin{array}{c}\mathrm{mQ}, \\
\mathrm{kJ}\end{array}$ & $\begin{array}{c}\mathrm{I}, \\
\mathrm{Ns}\end{array}$ & $\begin{array}{c}\mathrm{I} / \mathrm{m}, \\
\mathrm{m} / \mathrm{s}\end{array}$ & $\begin{array}{c}\mathrm{J}, \\
\mathrm{Pa} \cdot \mathrm{s}\end{array}$ & $\begin{array}{c}\Delta \mathrm{PM}, \\
\mathrm{MPa}\end{array}$ & $\begin{array}{c}\mathrm{E}, \\
\mathrm{MJ} / \mathrm{m} 2\end{array}$ & $\begin{array}{c}\mathrm{m}, \\
10-3 \mathrm{~kg}\end{array}$ & $\begin{array}{c}\mathrm{mQ}, \\
\mathrm{kJ}\end{array}$ & $\begin{array}{c}\mathrm{I}, \\
\mathrm{Ns}\end{array}$ & $\begin{array}{c}\mathrm{I} / \mathrm{m}, \\
\mathrm{m} / \mathrm{s}\end{array}$ & $\begin{array}{c}\mathrm{J}, \\
\mathrm{Pa} \cdot \mathrm{s}\end{array}$ & $\begin{array}{c}\Delta \mathrm{PM}, \\
\mathrm{MPa}\end{array}$ & $\begin{array}{c}\mathrm{E}, \\
\mathrm{MJ} / \mathrm{m} 2\end{array}$ \\
\hline \multicolumn{8}{|c|}{$\mathrm{L}=1 \mathrm{~m}, \mathrm{r}=0,075 \mathrm{~m}, \mathrm{~S}=0,0177 \mathrm{~m} 2$} \\
\hline \multicolumn{8}{|c|}{ Blasts at opened end of the tubes according to scheme of figure $2 \mathrm{a}$} \\
\hline 5,5 & 26,3 & 14,4 & 2606 & 810 & 5,2 & 0,745 & 5,5 & 26,3 & 13,7 & 2495 & 2060 & 28 & 1,98 \\
\hline 6,0 & 28,7 & 17,6 & 2933 & 1000 & 5,5 & 0,81 & 5,9 & 28,2 & 14 & 2375 & 2100 & 30 & 2,12 \\
\hline 8,5 & 40,6 & 23,9 & 2436 & 1350 & 7,7 & 1,15 & 8,1 & 38,7 & 17 & 2102 & 2600 & 43 & 2,91 \\
\hline 11,0 & 52,5 & 27,9 & 2536 & 1580 & 10 & 1,49 & 11,0 & 52,5 & 24,5 & 2234 & 3700 & 62 & 3,96 \\
\hline 15,9 & 76,0 & 37,8 & 2381 & 2140 & 13,8 & 2,15 & 15,3 & 73,1 & 33 & 2162 & 5000 & 90 & 5,50 \\
\hline \multicolumn{10}{|c|}{ Blasts at closed end of the tubes according to scheme of figure 2b } & & \\
\hline 5,5 & 26,3 & 27,4 & 4988 & 1550 & 9,1 & 1,49 & 5,5 & 26,3 & 23,6 & 4286 & 3550 & 61 & 3,96 \\
\hline 8,5 & 40,6 & 40,7 & 4789 & 2300 & 14,8 & 2,30 & 8,1 & 38,7 & 34,4 & 4246 & 5180 & 94 & 5,83 \\
\hline 11 & 52,5 & 51,4 & 4670 & 2902 & 19,5 & 2,98 & 13,7 & 65,4 & 56,2 & 4105 & 8470 & & 9,85 \\
\hline 15,9 & 76,0 & 71,1 & 4470 & 4015 & 29 & 4,30 & 15,3 & 73,08 & 62,7 & 4101 & 9450 & & 11,01 \\
\hline
\end{tabular}

Table 2. Results of measurements and calculations the parameters of flowing out shock waves for blasts at opened and closed ends of the tubes.

\begin{tabular}{|c|c|c|c|c|c|c|c|c|c|}
\hline $\begin{array}{c}\mathrm{m}, \\
10-3 \mathrm{~kg}\end{array}$ & $\begin{array}{c}\mathrm{mQ}, \\
\mathrm{kJ}\end{array}$ & $\begin{array}{l}\Delta \mathrm{Pm}, \\
\mathrm{MPa}\end{array}$ & $\begin{array}{l}\tau+ \\
\mathrm{ms}\end{array}$ & $\begin{array}{c}\mathrm{J}+, \\
\mathrm{Pa} \cdot \mathrm{s}\end{array}$ & $\begin{array}{c}\Delta \mathrm{Pmc}, \\
\mathrm{MPa}\end{array}$ & $\begin{array}{c}\tau+\mathrm{c} \\
\mathrm{ms}\end{array}$ & $\begin{array}{l}\mathrm{J}+\mathrm{c}, \\
\mathrm{Pa} \cdot \mathrm{s}\end{array}$ & $\begin{array}{l}\mathrm{X}, \\
\mathrm{m}\end{array}$ & $\begin{array}{c}\mathrm{E} / \mathrm{X}, \\
\mathrm{MJ} / \mathrm{m} 3\end{array}$ \\
\hline \multicolumn{10}{|c|}{ Blasts at opened end of the tubes according to scheme of figure $2 \mathrm{c}$} \\
\hline \multicolumn{10}{|c|}{$\mathrm{L}=1 \mathrm{~m}, \mathrm{r}=0,075 \mathrm{~m}, \mathrm{~S}=0,0177 \mathrm{~m} 2$} \\
\hline 5,7 & 27,4 & 1,3 & 0,6 & 280 & 0,92 & 1 & 4599 & 0,98 & 0,79 \\
\hline 5,7 & 27,4 & 1,2 & 0,44 & 180 & 0,90 & 1 & 451 & 1,0 & 0,77 \\
\hline 5,7 & 27,4 & 0,9 & 0,4 & 190 & 0,90 & 1 & 4519 & 1,0 & 0,77 \\
\hline 5,7 & 27,4 & 0,7 & 0,2 & 90 & 0,85 & 1 & 425 & 1,07 & 0,72 \\
\hline 7,0 & 33,6 & 1,2 & 0,65 & 290 & 1,09 & 1 & 544 & 0,98 & 0,96 \\
\hline 7,0 & 33,6 & 1,1 & 0,48 & 210 & 1,07 & 1 & 534 & 1,0 & 0,95 \\
\hline 15,3 & 73,4 & 2,01 & 0,6 & 520 & 2,08 & 1 & 1040 & 1,0 & 2,07 \\
\hline \multicolumn{10}{|c|}{$\mathrm{L}=0,5 \mathrm{~m}, \mathrm{r}=0,046 \mathrm{~m}, \mathrm{~S}=0,00664 \mathrm{~m} 2$} \\
\hline 0,81 & 3,9 & 0,72 & 0,4 & 120 & 0,75 & 0,5 & 188 & 0,48 & 0,61 \\
\hline 0,81 & 3,9 & 0,7 & 0,35 & 110 & 0,73 & 0,5 & 182 & 0,50 & 0,58 \\
\hline 0,81 & 3,9 & 0,64 & 0,18 & 58 & 0,67 & 0,5 & 169 & 0,546 & 0,53 \\
\hline 0,81 & 3,9 & 0,6 & 0,24 & 72 & 0,67 & 0,5 & 169 & 0,546 & 0,53 \\
\hline 7,0 & 33,6 & 4,5 & 0,42 & 945 & 4,84 & 0,5 & 1209 & 0,48 & 5,25 \\
\hline 7,0 & 33,6 & 4,2 & 0,37 & 777 & 4,65 & 0,5 & 1163 & 0,50 & 5,04 \\
\hline 15,3 & 73,4 & 9,2 & 0,35 & 1420 & 9,58 & 0,5 & 2394 & 0,50 & 11,01 \\
\hline \multicolumn{10}{|c|}{ Blasts at closed end of the tubes according to scheme of figure $2 \mathrm{~d}$} \\
\hline \multicolumn{10}{|c|}{$\mathrm{L}=1 \mathrm{~m}, \mathrm{r}=0,075 \mathrm{~m}, \mathrm{~S}=0,0177 \mathrm{~m} 2$} \\
\hline 5,7 & 27,4 & 1,5 & 0,65 & 577 & 1,64 & 1 & 821 & 0,98 & 1,58 \\
\hline 7,0 & 33,6 & 2 & 0,70 & 709 & 1,96 & 1 & 981 & 0,98 & 1,94 \\
\hline 8,5 & 40,8 & 2,2 & 0,71 & 904 & 2,32 & 1 & 1162 & 0,98 & 2,35 \\
\hline 11 & 52,8 & 2,7 & 0,70 & 1120 & 2,92 & 1 & 1460 & 0,98 & 3,04 \\
\hline 15,3 & 73,4 & 3,5 & 0,72 & 1551 & 3,90 & 1 & 1949 & 0,98 & 4,23 \\
\hline 15,9 & 76,3 & 3,7 & 0,75 & 1605 & 4,06 & 1 & 2031 & 0,98 & 4,40 \\
\hline \multicolumn{10}{|c|}{$\mathrm{L}=0,5 \mathrm{~m}, \mathrm{r}=0,046 \mathrm{~m}, \mathrm{~S}=0,00664 \mathrm{~m} 2$} \\
\hline 0,81 & 3,9 & 1,5 & 0,45 & 223 & 1,33 & 0,5 & 333 & 0,48 & 1,22 \\
\hline 5,5 & 26,4 & 6,7 & 0,48 & 1405 & 7,33 & 0,5 & 1832 & 0,48 & 8,28 \\
\hline 7,0 & 33,6 & 8,9 & 0,49 & 1606 & 9,17 & 0,5 & 2293 & 0,48 & 10,54 \\
\hline 8,1 & 38,9 & 9,8 & 0,50 & 1750 & 10,51 & 0,5 & 2629 & 0,48 & 12,20 \\
\hline 13,7 & 65,8 & 16 & 0,55 & 2853 & 17,27 & 0,5 & 4318 & 0,48 & 20,63 \\
\hline 15,3 & 73,4 & 17,0 & 0,58 & 3530 & 19,19 & 0,5 & 4797 & 0,48 & 23,04 \\
\hline
\end{tabular}




\section{Discussion}

Parameters of the positive phase of shock waves at blasts in open tubes were calculated from empirical formulas adduced in [8] for overpressure $\Delta \mathrm{Pm}$ in the range from 0,1 to $50 \mathrm{MPa}$.

$$
\begin{gathered}
\Delta \mathrm{Pm}=(0,79 \mathrm{E} / \mathrm{X}+0,39(\mathrm{E} / \mathrm{X}) 0,5) \cdot \exp (-0,004 \mathrm{X} / \mathrm{r}), \tau+=\mathrm{X}, \\
\mathrm{J}+=1000 \Delta \mathrm{Pm} \tau+/ 2
\end{gathered}
$$

The overpressure $\triangle \mathrm{PM}$ of the reflected from pendulum shock waves in tubes were calculated from the empirical formulas

$$
\begin{gathered}
\Delta \mathrm{PM}=\mathrm{Kp}(0,79 \mathrm{E} / \mathrm{X}+0,39(\mathrm{E} / \mathrm{X}) 0,5) \cdot \exp (-0,004 \mathrm{X} / \mathrm{r}), \\
\mathrm{Kp}=5,48 \Delta \mathrm{Pm} 0,245
\end{gathered}
$$

Where $\Delta \mathrm{Pm}$ and $\Delta \mathrm{PM}$ in $\mathrm{MPa}, \tau+$ in $\mathrm{ms}, \mathrm{X}$ in $\mathrm{m}, \mathrm{J}+$ in $\mathrm{Pa} \cdot \mathrm{s}, \mathrm{E}=\mathrm{mQ} / 2 \mathrm{~S}$ or $\mathrm{E}=\mathrm{mQ} / \mathrm{S}$ in $\mathrm{MJ} / \mathrm{m} 2$ are the similarity parameters for blasts at open or closed tube ends respectively.

In figures 3, 4 are compared the calculations and measurements for dependencies $\triangle \mathrm{PM}$ and $\mathrm{J}$ on the explosive energy mQ for the reflected shock wave of blasts at closed and open ends of the tubes. At equal masses of explosives and lengths of tubes the $\triangle \mathrm{PM}$ and $\mathrm{J}$ are about twice higher for blasts at the closed tube end.

At table 2 compares the measured data with calculated (marked with a sub index "c") according to formula (1) for overpressures $\Delta \mathrm{Pm}$, duration $\tau+$ and specific impulse $\mathrm{J}+$ positive phase of shock waves at the open output of the tubes for blasts at the open and closed input ends of the tubes, when $\mathrm{E}=\mathrm{mQ} / 2 \mathrm{~S}$ and $\mathrm{mQ} / \mathrm{S}$ respectively. Measured impulses $\mathrm{J}+$ and durations $\tau+$ of shock waves at the output of the tubes are much lower than the calculated values $\mathrm{J}+\mathrm{c}$ and $\tau+\mathrm{c}$ due to not taking into account in the calculation lateral unloading of shock waves exits from the tube.

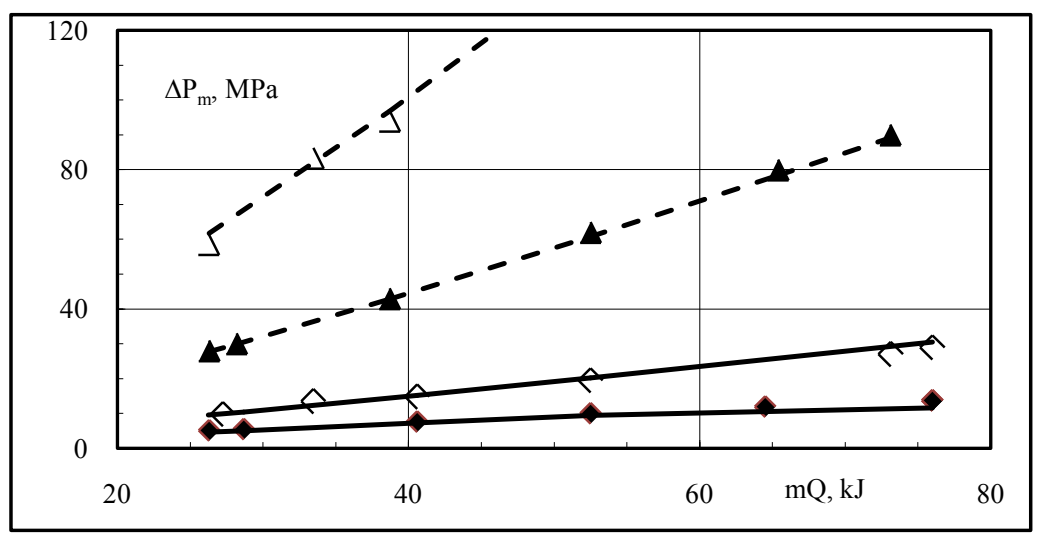

Figure 3. Dependences of the overpressure $\triangle \mathrm{PM}$ on blast energy $\mathrm{mQ}$ in reflected shock waves for blasts at open and closed input ends of the tubes- solid and transparent markers respectively. The solid and the dotted lines - calculations for $\mathrm{L}=1$ and $0,5 \mathrm{~m}$.

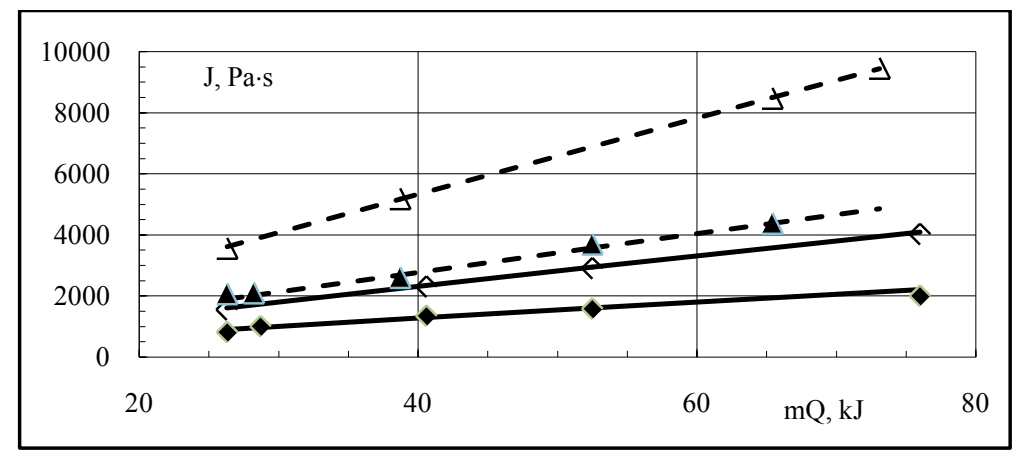

Figure 4. Dependences of the specific impulse $J$ on blast energy $\mathrm{mQ}$ in reflected shock waves for blasts at open and closed input ends of the tubes- solid and transparent markers respectively. The solid and the dotted lines - calculations for $\mathrm{L}=1$ and $0,5 \mathrm{~m}$. 


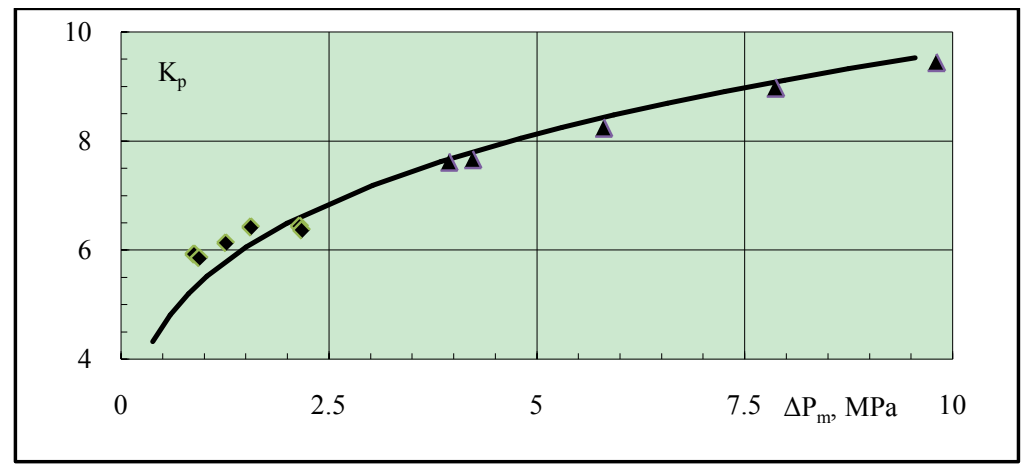

Figure 5. Dependences of the reflection coefficient $\mathrm{Kp}$ on $\Delta \mathrm{Pm}$. Triangles and rhombuses - measuring data in tubes by length $\mathrm{L}=0,5$ and $1 \mathrm{~m}$, line calculation by the formula (2).

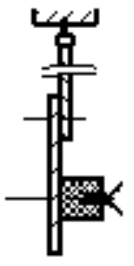

1)

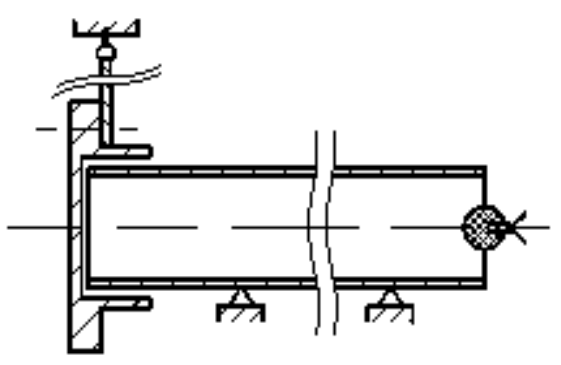

3)

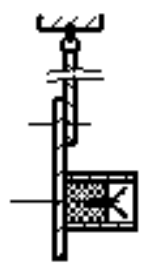

2)

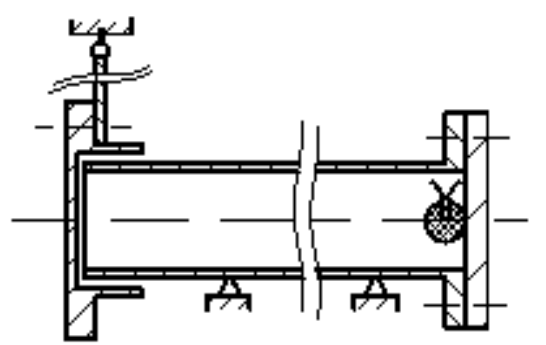

4)

\begin{tabular}{|c|c|c|c|c|}
\hline Scheme of the blasts & 1 & 2 & 3 & 4 \\
\hline Relative impulse I/m, m/s & 1200 & 2200 & 2400 & 4900 \\
\hline
\end{tabular}

Figure 6. Four schemes of explosives blasts measured by the pendulum and corresponding relative impulses $\mathrm{I} / \mathrm{m}$ of shock waves. Contact blasts of charges without the shell and in the hard shell - 1,2. Explosives blasts at the entrance of open and closed tubes - 3, 4 .

Figure 5 shows both calculated from formula (2) and measured values of reflection coefficients from rigid wall $\mathrm{Kp}$ at different overpressures $\Delta \mathrm{Pm}$. Calculated values the coefficient of adiabate air were taken from [1]. Measured reflection coefficients $\mathrm{Kp}$ consistent with the calculations within the experimental error. The measured reflection coefficient for specific impulse of shock wave was $\mathrm{Kj}=2.06$.

The impulses I of the pendulum at blasts in tubes and at contact blasts were compared. Figure 6 shows the four different schemes of the explosives blasts on pendulum and table with typical relative impulse values $\mathrm{I} / \mathrm{m}$ for explosives at a detonation velocity $\mathrm{D}=7500 \mathrm{~m} / \mathrm{s}$ and density of 1600 $\mathrm{kg} / \mathrm{m} 3$. The relative impulses $\mathrm{I} / \mathrm{m}$ of the reflected shock waves in tubes and at contact blasts [1 - 3] were compared. For contact blast of charge figure 6 (1) without shell with a diameter equal diameter barrier $\mathrm{I} / \mathrm{m}=0,081 \mathrm{D}=611 \mathrm{~m} / \mathrm{s}$. When the charge diameter was much less than the diameter of barrier an impulse was doubled to $\mathrm{I} / \mathrm{m}=1220 \mathrm{~m} / \mathrm{s}$. At contact blast of charge in a rigid shell according scheme figure $6(2) \mathrm{I} / \mathrm{m}=(8 / 27) \mathrm{D}=2200 \mathrm{~m} / \mathrm{s}[1-3]$. The blasts in tubes under the schemes figure $6(3,4)$ can increase by almost an order the overpressure and twice the relative impulse at reflection of the direct shock wave from barrier. In the scheme of figure 6(3) the average value of relative impulse was $\mathrm{I} / \mathrm{m}=2400 \mathrm{~m} / \mathrm{s}$. At the blasts at the closed end of the tube figure 6 (4) overpressures and impulses shock waves increases by about two times and characteristic values of relative impulses I/m at the barrier can reach $5000 \mathrm{~m} / \mathrm{s}$.

Thus the efficiency of the blast action on the pendulum is higher for blasts in the tubes compared with contact blasts. 


\section{Conclusions}

Experimental study and calculations parameters of the direct, reflected and flowing out shock waves were carried out at blasts on the open and closed ends of the tubes different lengths and diameters.

It is shown that the overpressure and specific impulse of direct shock waves at the blasts on closed end of the tubes is almost two times more than at the blast on open end. Upon reflection of the shock waves from rigid wall in tube can be almost on order increased overpressure and twice the specific impulse. It is shown advantages of the action of blasts in tubes for a number of engineering applications compared with contact blasts.

\section{Acknowledgements}

I am grateful to Prof. G.G. Kocharyan and Prof. V.M. Tsvetkov for useful discussion of the directions beneficial use of blasts in tubes in science and technology and constructive suggestions to improve this article.

\section{REFERENCES}

[1] W.E. Baker, P.A. Cox, P.S. Westine, J.J. Kulesz, R.A. Strehlow. Explosion Hazard and Evaluation, Elsevier Scientific Publishing Company, New York, 1983.

[2] L.N. Back, G. Varsi. Detonation Propulsion for High Pressure Environments, 1AIAA Journal, Vol.12, No 8, 1123-1130. 1974

[3] G. Varsi, L.N. Back. K. Kim. Blast wave analysis for detonation propulsion, Journal Acta Astronautics, No.3, 141 $156,1976$.

[4] B.D. Khristoforov. The effect of properties of the source on the action of explosion in air and water, Journal of Combustion, Explosion and Shock Waves,Vol. 40, No.6, 714 $-719,2004$.

[5] B.D. Khristoforov. Experimental Modeling of Impact of Space Dust and Debris on Flying Vehicles and their Components, Journal Cosmic Research, Vol. 49, No.3, 263 $268,2011$.
[6] V.O. Solov'ev, B.D. Khristoforov. Modeling the action of $\mathrm{X}$-ray radiation on the walls of explosion chambers of pulsed nuclear power plants, Combustion Explosion and Shock Waves, Springer New York, Vol.44, No 5, 601 - 606, 2008.

[7] D.A. Freiwald. Approximate blast wave theory and experimental data for shock trajectories in linear explosive driven shock tubes, Journal of Applied Physics, Vol.43. No.5, $2224-2226,1972$.

[8] E.K. Anderzhanov, B.D. Khristoforov. The study of shock waves in tube at spherical explosion, Journal of Applied Mechanics and Technical Physics, No.5, 25 - 27, 1988.

[9] A,V. Adushkin, V.N. Burchik, A.I. Goncharov, V.I. Kulikov, B.D. Khristoforov,V.I. Tsykanovskii. Seismic, hydroacoustic, and acoustic action of underwater explosions, Journal of Combustion, Explosion and Shock Waves, Vol. 40, No.6, 707-713, 2004

[10] V.V. Garnov, B.G. Goryunov, N.M. Sitsinskaya. High-speed photographic recording equipment for recording nuclear explosions and other fast processes, Journal of Combustion, Explosion and Shock Waves, Vol. 40. No.6, 729-733, 2004.

\section{Designations}

$\mathrm{L}, \mathrm{r}-$ length and radius of tubes in $\mathrm{m}$.

$\mathrm{S}=\pi \mathrm{r}^{2}$ - area of section tube in $\mathrm{m}^{2}$.

$\mathrm{Q}$ - heat of blast in $\mathrm{MJ} / \mathrm{kg}$.

$\mathrm{m}$ - explosive mass in $\mathrm{kg}$.

I - impulse of reflected shock wave in tube determined from the pendulum deviation in Ns.

$\mathrm{I} / \mathrm{m}$ - relative impulse in $\mathrm{m} / \mathrm{s}$.

$\mathrm{J}$ - specific impulse in $\mathrm{Pa} \cdot \mathrm{s}$.

$\Delta \mathrm{P}_{\mathrm{m}}$ - overpressure of shock wave into tube in $\mathrm{Pa}$.

$\Delta \mathrm{P}_{\mathrm{M}}$ - over pressure of reflected shock wave into tube in $\mathrm{Pa}$.

$\tau_{+}$- duration of the positive phase of the shock wave in ms. $\mathrm{J}_{+}-$specific impulse of the positive phase shock wave in $\mathrm{Pa} \cdot \mathrm{s}$.

$\Delta \mathrm{P}_{\mathrm{mc}}, \tau_{+\mathrm{c}}, \mathrm{J}_{+_{\mathrm{c}}},-$ calculated from empirical formulas (1) parameters of the shock wave in table 2 .

$\mathrm{E}$ - specific energy in $\mathrm{MJ} / \mathrm{m}^{2}$

$\mathrm{X}$ - distance from charge to shock wave front in $\mathrm{m}$.

$\mathrm{K}_{\mathrm{p}}, \mathrm{K}_{\mathrm{j}}$ - reflection coefficients for overpressure and impulse of shock waves. 